\title{
28 Research Square \\ Effect of Using Limestone Fines on the Chemical Shrinkage of Pastes and Mortars
}

Jamal Khatib ( $\boldsymbol{\sim}$ j.khatib@bau.edu.lb )

Beirut Arab University

Rawan Ramadan

Beirut Arab University

Hassan Ghanem

Beirut Arab University https://orcid.org/0000-0002-6217-2743

Adel ElKordi

Beirut Arab University

\section{Research Article}

Keywords: Limestone fines, Chemical shrinkage, UPV, Density, Compressive strength, Pastes, Mortars

Posted Date: November 24th, 2021

DOI: https://doi.org/10.21203/rs.3.rs-924279/v1

License: (c) (1) This work is licensed under a Creative Commons Attribution 4.0 International License. Read Full License

Version of Record: A version of this preprint was published at Environmental Science and Pollution Research on January 6th, 2022. See the published version at https://doi.org/10.1007/s11356-022-18496-5. 


\section{Abstract}

The main aim of this study is to examine the effect of incorporating limestone fines (LF) on chemical shrinkage of pastes and mortars. For this purpose, five paste and five mortar mixes were prepared with 0, 5, 10, 15 and 20\% (by weight) LF as replacement of cement. The water to binder ratio $(\mathrm{w} / \mathrm{b})$ was $0.45 \mathrm{for}$ all mixes. The sand to binder $(\mathrm{s} / \mathrm{b})$ ratio in the mortar mixes was 2. Testing included chemical shrinkage, compressive strength, density and ultrasonic-pulse velocity (UPV). Chemical shrinkage was tested each hour for the first $24 \mathrm{hrs}$, and thereafter each 2 days until a total period of 90 days. Furthermore, compressive strength and UPV tests were conducted at 1 day, 7, 28 and 90 days of curing. The results show that the long-term chemical shrinkage of pastes was found to increase with the increase in LF content up to 15\%. Beyond this level of replacement, the chemical shrinkage started to decrease. However, the chemical shrinkage for mortars increased with the increase in LF content up to $10 \%$ LF and a decrease was observed beyond this level. It was also noticed that compressive strength for pastes and mortars attained the highest value for mixes containing 10 and $15 \%$ LF. The trend in the UPV results is somewhat similar to those of strength. Density for pastes and mortars increased up to $15 \%$ LF followed by a decrease at $20 \%$ replacement level. Correlations between the various properties were conducted. It was found that an increase in chemical shrinkage led to an increase in compressive strength.

\section{Introduction}

Concrete is one of the dominant building materials in the construction industry. The main problem of concrete is the early-age cracking which is caused by chemical shrinkage (Safiuddin et al. 2018). Chemical shrinkage is defined as the internal volume change of cement paste resulting from the hydration of cementitious materials. The volume of hydration products is smaller than the sum of both cement and water volumes (Zhutovsky et al. 2010). This phenomenon is also known as Le Chatelier contraction. Le Chatelier reported that total chemical shrinkage for normal Portland cement was about $4.6 \%$ by weight of cement (Le chatelier. 1900). Chemical shrinkage is considered as an essential property of Portland cement and also assumed proportional to the degree of hydration (Zhutovsky et al. 2008). Geiker and Knudsen. (1982) mentioned that chemical shrinkage is independent of water to cement ratio during the early age of hydration. However, other authors (Zhang et al. 2010; Zhang et al. 2020) reported that chemical shrinkage is dependent on w/c ratio. Chemical shrinkage is also a function of the initial cement content (Zhutovsky et al, 2010).

Three main measurement methods for chemical shrinkage have been used: dilatometry, pyconometry and gravimetry. Amid these test methods, dilatometry is the most popular method used by many authors (Justnes et al. 1994; Tazawa et al. 1995; Justnes et al. 1996; Persson et al. 1997; Justnes et al. 1998; Justnes et al. 1999; Hammer et al. 1999; Justnes et al. 2000; Beltzung et al. 2000; Charron et al. 2001; Charron et al. 2002; Zhang et al. 2013; Liao et al. 2014). Dilatometry method as reported by Lura. 2003 measures the drop in level of water in a hydrating cement paste system using a graduated pipette or a suitable graduated tube. This drop of water in the pipette represents the chemical shrinkage (volume change) of cement paste.

The addition of supplementary materials as partial replacement of cement will mainly affect the hydration process which in turn will affect the chemical shrinkage. Several studies investigated the influence of incorporating supplementary materials on chemical shrinkage. Wild et al. (1998) found that incorporating up to $15 \%$ metakaolin (MK) enhanced the chemical shrinkage. This finding is also reported by Markandeya et al. (2019). Moreover, Lu et al. (2020) noted that using Blast Furnace Slag (BFS) in concrete achieved higher chemical shrinkage than those containing fly ash (FA) and silica fume (SF). Furthermore, Wang et al. (2020) indicated that chemical shrinkage increased as the percentage of nano-silica increased.

Over the last decades, the incorporation of limestone as cement replacement has been investigated (Bonavetti et al. 2000; Tsivilis et al. 2000; Heikal et al. 2000; Matschei et al. 2007; Lothenbach et al. 2008). Limestone is a sedimentary rock consisting of calcium carbonate $\left(\mathrm{CaCO}_{3}\right)$. It is used for various purposes especially in concrete production. Limestone is usually considered as an inert filler material that produces an acceleration in the chemical shrinkage and hydration process during the early ages (Bouasker et al. 2008; Weerdt et al. 2011). This filler played the role of nucleation sites for hydrates (Bouasker et al. 2008; Weerdt et al. 2011). Several studies reported the effect of replacing limestone fines (LF) on the chemical shrinkage of concrete. Using LF in cement based mixes affected the chemical shrinkage (Menendez et al. 2003; Wang et al.

Page $2 / 21$ 
2010; Weerdt et al. 2011). Another study confirmed that incorporating LF with calcined clay (CC) increased rapidly the chemical shrinkage within the first 7 days (Du et al. 2020).

There has been some research on the chemical shrinkage of cement paste incorporating LF. However, there is hardly any research on the chemical shrinkage of mortar. Also there does not seem studies on comparing the effect of incorporating limestone fines on the chemical shrinkage of cement paste and mortar. Moreover, the cement industry produces a large amount of $\mathrm{CO}_{2}$ emission (7\%), which result in greenhouse effect that can contribute towards the rise in the earth temperature (Thongsanitgarn et al. 2012; Meddah et al. 2013). Therefore, incorporating LF may reduce such problem. Therefore, the main objective of this study is to examine on the effect of using LF on the chemical shrinkage of pastes and mortars. Other properties such as density, compressive strength and UPV were also conducted.

\section{Experimental Work}

\section{Materials}

One commercial Portland cement Type I was used in this study (Portland cement PA-L $42.5 \mathrm{~N}$ ). The limestone fine (LF) was extracted from Lebanon quarries. Figs. 1 and 2 show the particle size distribution of limestone and particle size distribution of cement respectively. The limestone was firstly ground before sieving through the $300 \mu \mathrm{m}$ sieve. The density of LF is found to be $2.7 \mathrm{~g} / \mathrm{cm}^{3}$. The chemical compositions for cement and limestone are shown in Table 1. The natural sand used had a fineness modulus of 2.8 .

Table 1 Chemical composition of cement and LF

\begin{tabular}{cccccccccc} 
Oxide & $\mathrm{SiO}_{2}$ & $\mathrm{AL}_{2} \mathrm{O}_{3}$ & $\mathrm{Fe}_{2} \mathrm{O}_{3}$ & $\mathrm{CaO}$ & $\mathrm{MgO}$ & $\mathrm{SO}_{3}$ & $\mathrm{Na}_{2} \mathrm{O}$ & $\mathrm{K}_{2} \mathrm{O}$ & L.0.I \\
\hline Cement & 18.53 & 3.93 & 3.06 & 61.78 & 1.74 & 2.92 & 0.18 & 0.47 & 6.3 \\
\hline LF & 5.17 & 1.65 & 0.77 & 50.98 & 0 & 0.21 & 0.18 & 0.12 & 39.64
\end{tabular}

\section{Mix proportions}

Five paste mixes and five mortar mixes were employed. The cement in the paste and mortar mixes are partially replaced with 0 , $5,10,15$ and $20 \%$ LF (by weight). The water to binder (w/b) ratio for all mixes was kept constant at 0.45 . In the mortar mixes, the sand to binder (s/b) ratio was 2 . The binder consists of cement and LF. The total number of samples tested was 100 . The details of paste and mortar mix proportions are presented in Tables 2 and 3 respectively.

Table 2 Mix proportions of paste mixes

\begin{tabular}{|lcll|}
\hline & \multicolumn{3}{c|}{ Quantity $\left(\mathrm{kg} / \mathrm{m}^{3}\right)$} \\
\hline PASTE CODE & Cement & $\mathrm{LF}^{*}$ & Water \\
\hline P0 & 1303 & 0 & 586 \\
\hline P5 & 1237 & 66 & 586 \\
\hline P10 & 1177 & 126 & 586 \\
\hline P15 & 1123 & 180 & 586 \\
\hline P20 & 1074 & 229 & 586 \\
\hline
\end{tabular}

*LF: limestone fines

Table 3 Mix proportions of mortar mixes 


\begin{tabular}{ccccc}
\multicolumn{5}{c}{ Quantity $\left(\mathrm{kg} / \mathrm{m}^{3}\right)$} \\
\hline Mortar code & Cement & LF* & Sand & Water \\
\hline M0 & 657 & 0 & 1314 & 296 \\
\hline M5 & 625 & 32 & 1314 & 296 \\
\hline M10 & 595 & 62 & 1314 & 296 \\
\hline M15 & 569 & 88 & 1314 & 296 \\
\hline M20 & 544 & 113 & 1314 & 296
\end{tabular}

*LF : limestone fines

\section{Sample preparation and test procedure}

Chemical shrinkage was tested according to ASTM C1608 (2007). The cement and LF were dry mixed for two minutes. In the case of mortar, sand was added to the dry materials and also mixed for two minutes. After adding the prescribed water to the blended materials, mixing continued until homogeneity was attained. The mixing was conducted by a spatula due to the small volume of specimens. After mixing, the paste or mortar was placed in a $250 \mathrm{ml}$ glass bottles by using a funnel to a depth of around $1.8 \mathrm{~cm}$ equivalent to approximately $30 \mathrm{gm}$ of paste. The bottle was weighed before and after the addition of paste or mortar sample. The bottles were slightly shaken in order to maintain the same level and to eliminate air voids. After that, distilled water was added slowly on the top surface of the sample using a straw so that the surface layer of the sample is not disturbed. For each bottle, a $2 \mathrm{ml}$ graduated pipette was inserted through a hole in a rubber stopper. The stoppers were immersed in water for a few hours to avoid any water absorbed by the rubber. Then water was slowly added using a syringe till the top of the pipette. This level of water was recorded as the initial value. In order to prevent water evaporation, a drop of oil was placed on the top level of water in each pipette. The bottles were then placed in a room at constant temperature $\left(25^{\circ} \mathrm{C}\right)$ as shown in Fig. 3. The level of water in the pipette was observed each hour for the first $24 \mathrm{hrs}$, and thereafter each 2 days until a period of 90 days. The drop of water in the pipette represents the volume change (i.e. chemical shrinkage) which was converted in milliliters per gram of binder $(P C+L F)$. Each chemical shrinkage value determined is the average of two values from two replicate specimens. The chemical shrinkage measurements setup is shown in Fig. 4.

For compressive strength and UPV test, standards steel cubic molds of dimensions $50 \mathrm{~mm} \times 50 \mathrm{~mm} \times 50 \mathrm{~mm}$ were used. Compressive strength was measured according to ASTM C109 (2016) using a universal testing machine with a rate of loading of $3 \mathrm{kN} / \mathrm{s}$. UPV test was applied according with ASTM C597 (2016) and was calculated as follow:

$V=D / T \quad(1)$

where: $D$ is the distance separating the transmitter and the receiver $(\mathrm{km})$ and $T$ is the propagation time for the pulse to get throughout the specimen (sec).

Moreover, the density was calculated according to ASTM C188 (2014) and was calculated as follow:

$$
D=\frac{M}{V}
$$

Where: $\mathrm{D}$ is the density $\left(\mathrm{g} / \mathrm{cm}^{3}\right), \mathrm{M}$ and $\mathrm{V}$ are the mass and volume of the cube respectively.

\section{Results And Discussion}


The results of chemical shrinkage, compressive strength, density and UPV tests, data analysis and the correlations are reported in the following sections.

\section{Chemical shrinkage}

The results of chemical shrinkage of paste and mortar specimens during the first 24 hrs are presented in Figs. 5 and 6 respectively. The zero time was considered when water was added to the cement. At $24 \mathrm{hrs}$, the chemical shrinkage of paste with $0 \% \mathrm{LF}$ reached a value of $0.026 \mathrm{ml} / \mathrm{g}$. This value increases to a maximum value of $0.047 \mathrm{ml} / \mathrm{g}$ for pastes with $15 \% \mathrm{LF}$. As deduced from Fig. 6, the chemical shrinkage of mortars at $0 \% \mathrm{LF}$ is $0.029 \mathrm{ml} / \mathrm{g}$. This value goes up to $0.037 \mathrm{ml} / \mathrm{g}$ at $5 \% \mathrm{LF}$ then subsequently drops with the incorporation of 10, 15 and $20 \%$ LF. This can be interpreted by the fact that the existence of LF causes an acceleration in the chemical shrinkage for the first few hours. This finding is consistent with that of Bouasker et al. (2008).

The results of chemical shrinkage of pastes and mortars for 90 days are shown in Figs. 7 and 8 respectively. Those figures show similar characteristics. For the first 3 days, the chemical shrinkage values are approximately similar for all mixes in paste and mortar specimens. At 90 days, the chemical shrinkage of pastes with $0 \% \mathrm{LF}$ attains a value of $0.107 \mathrm{ml} / \mathrm{g}$. This value increases to $0.133 \mathrm{ml} / \mathrm{g}$ at $5 \% \mathrm{LF}$ then slightly drops with the addition of $10 \% \mathrm{LF}(0.13 \mathrm{ml} / \mathrm{g})$. After this slight decrease, the chemical shrinkage increases to the optimum value of $0.194 \mathrm{ml} / \mathrm{g}$ at $15 \% \mathrm{LF}$. For a replacement of $20 \%$, the chemical shrinkage exhibits a sharp decline and reaches a value of $0.12 \mathrm{ml} / \mathrm{g}$. During the $1^{\text {st }}$ day, the inclusion of LF with the same percentages in mortars has mostly the same effect as pastes but with a smaller value. As shown in Fig. 8, the chemical shrinkage achieves a value of $0.121 \mathrm{ml} / \mathrm{g}$ at $0 \% \mathrm{LF}$. This value slightly decreases to about $0.117 \mathrm{ml} / \mathrm{g}$ for an amount of $5 \% \mathrm{LF}$ then goes up to the maximum value of $0.132 \mathrm{ml} / \mathrm{g}$ at $10 \% \mathrm{LF}$. After that, the chemical shrinkage displays a sharp drop at 15 and $20 \%$ LF. The sharp decline occurs after the addition of 10 and $15 \%$ LF in mortar and paste samples respectively may be explained by the fact that with high amount of LF ( $\ 10$ and 15\%), as the curing time goes up, the formation of calciumcarboaluminate hydrate could consumed $\mathrm{CH}$. Therefore, the chemical effect of LF leads to the stabilization of the ettringite and could increase the solid volume of hydration products (external expansion) which decrease the total system volume (chemical shrinkage) (Wild et al. 1998; Menendez et al. 2003; Wang et al. 2010; Weerdt et al. 2011; Wang et al. 2018a, b). Besides, with the same $\mathrm{w} / \mathrm{b}$ ratio, since LF has minimal cementitious or pozzolanic properties, the substitution of cement with different percentages of LF increases the free water to react with cement particles. That is known as dilution effect (Wang et al. 2018a).

The inclusion of different percentages of LF enhances the chemical shrinkage of pastes and mortars. In order to clarify this finding, three explanations can be made. First of all, as chemical shrinkage is a direct result of the hydration reactions, the acceleration of the cement hydration in the presence of LF which acts as a filler refines the pore structure, reduces the porosity of cement (Wang et al. 2018b) and makes an increase in chemical shrinkage. Additionally, LF can also interact slowly with the monosulfoaluminate (Afm) to create monocarboaluminate (Afmc), which has a higher density than the Afm phase (Weerdt et al. 2011). Last point, LF with fine particle size provides nucleation sites for hydration products to precipitate, accelerates the hydration process, and enhances the hydration degree of cement (Wang et al. 2018). It was mentioned that the advanced precipitation of $\mathrm{C}-\mathrm{S}-\mathrm{H}$ on the surface of LF was due to the propinquity between configuration of $\mathrm{Ca}$ and $\mathrm{O}$ atoms in calcite and $\mathrm{CaO}$ layers in $\mathrm{C}-\mathrm{S}-\mathrm{H}$. With the increase of LF amount, additional nucleation sites would be available, and more hydration products could be absorbed (Wang et al. 2018a).

By comparing Figs. 7 and 8, it can be deducted that chemical shrinkage results for paste specimens are greater than those for mortars. For example, the addition of $5 \% \mathrm{LF}$ in pastes exhibits a value of $0.133 \mathrm{ml} / \mathrm{g}$ while shows a value of $0.117 \mathrm{ml} / \mathrm{g}$ in mortars. This is mainly due to the presence of sand which automatically reduce the amount of cement and LF and slow down the hydration process.

To further illustrate the influence of LF on the chemical shrinkage of paste and mortar specimens, Figs. 9 and 10 are displayed. The plots exhibit the change in volume against different percentages of $L F$ at various curing ages $(1,7,28,45 \& 90$ days) for paste and mortar samples respectively. For pastes (Fig. 9), the extreme drop in volume occurs at $15 \%$ LF and then subsequently decreases. On the other side, the extreme drop in volume for mortars occurs at $10 \%$ LF then successively declines 
(Fig. 10). Proportionally, as curing time increases, the chemical shrinkage of pastes and mortars goes up as well. For example, the volume changes for $5 \%$ LF in mortar and paste samples increases about 8 and $9 \%$ from 1 to 90 days respectively. The chemical shrinkage becomes much steeper as curing time increases in pastes and mortars (e.g. at 7 days). The comparative proportions of phases present at specific curing time depends on LF content. For a specific LF content, as the curing time increases, $\mathrm{CH}$ is consumed (Wild et al. 1998; Wang et al. 2018a). Accordingly, the $\mathrm{CH}$ content of system drops and as a result, the $\mathrm{CH}$ /LF ratio will decline. Similarly, this last finding is also present when LF content increases (Wild et al. 1998; Wang et al. 2018a).

\section{Compressive strength}

The results of the compressive strength for pastes and mortars are presented in Figs. 11 and 12 respectively. Compressive strength measurements were carried out at 1, 7, 28 \& 90 days. As shown in these plots, the compressive strength of paste and mortar specimens for $15 \%$ and $10 \%$ LF respectively displays the highest strength among all percentages. For example, at 7 days, the compressive strength of pastes is $31.5 \mathrm{MPa}$ for the control mix. This value increases slightly with the addition of LF until achieving a maximum value of $35.8 \mathrm{MPa}$ for $15 \% \mathrm{LF}$ followed by a decrease in strength at $20 \%$. This strength loss of mixes with higher amount of LF $(\mathbb{1 5 \%} \mathrm{LF})$ may be due to the significant decrease of the potential cementitious material content, which is known as dilution effect (Kovler et al. 2006; Menadi et al. 2009). Furthermore, the compressive strength of mortars at 7 days is $22.4 \mathrm{MPa}$ at $0 \% \mathrm{LF}$. This value slightly increases to the maximum value of $23.4 \mathrm{MPa}$ at $10 \% \mathrm{LF}$ followed by a reduction in strength at 15 and $20 \%$ LF. This decrease is probably due to insufficient cement paste to coat all the LF and sand particles, which subsequently leads to a drop in compressive strength (Benabed et al. 2016). Those results are supported by previous studies (Soroka et al. 1976; Livesey et al. 1991; Voglis et al. 2005; Bentz et al. 2006; Bentz et al, 2009; Weerdt et al. 2010; Adel Mohammed et al. 2010; Güneyisi et al. 2011; Anusha et al. 2018). Same path is shown for the other curing durations. At 90 days, the maximum values of compressive strength are 70.4 and $31.6 \mathrm{MPa}$ for pastes and mortars respectively. This can be explained by the fact that LF has fines particles which enable it to be more reactive. LF can fill the pores between cement particles, this is known as filling effect (Wang et al. 2018a). The pastes and mortars become more compacted, hence increase the compressive strength. Moreover, the presence of chemical reaction between LF \& tricalcium aluminate $\left(\mathrm{C}_{3} \mathrm{~A}\right)$ to form calcium - carboaluminate leads to decrease the porosity of pastes and mortars and consequently increase their compressive strength (Thongsanitgarn et al. 2012).

The results of compressive strength for pastes ad mortars are mainly consistent with those of density. The density increases up to $15 \% \mathrm{LF}$ then drops for a higher amount of LF as shown in Table 4. For example, at 90 days, the density of pastes is 2.13 $\mathrm{g} / \mathrm{cm}^{3}$ at $0 \% \mathrm{LF}$. This value increases to the maximum value of $2.14 \mathrm{~g} / \mathrm{cm}^{3}$ with the addition of $15 \% \mathrm{LF}$ followed by a decline at $20 \%$. This increase is almost negligible (only $0.5 \%$ ). For mortars, the density at $0 \% \mathrm{LF}$ is $2.43 \mathrm{~g} / \mathrm{cm}^{3}$. This value goes up to the optimum value of $2.47 \mathrm{~g} / \mathrm{cm}^{3}$ at $15 \% \mathrm{LF}$ succeeded by a reduction at $20 \%$. This is due to cement hydration resulting from the reaction between LF and cement. The reduction occurring in the external dimensions of cement particles generates voids, a

perfect host for water. This phenomenon reduces durability as well as the density of paste. LF acts as a filler that fills the voids around cement particles up to the optimum. For higher filler content, voids are already totally filled. The extra amount of LF occupies the place of sand particles, thus decreases sand proportion and subsequently the density of mortars.

Besides, it is noted that the compressive strength values for pastes are greater than those for mortars. For example, the incorporation of $10 \% \mathrm{LF}$ in pastes shows a value of $56.4 \mathrm{MPa}$ at 28 days. However, it displays a value of $27.9 \mathrm{MPa}$ in mortars. This is well expected because the amount of cement in paste samples is greater than that for mortars. Accordingly, the amount of cement and LF exists in small amount in mortar mixtures. Thus, the reaction between cement and LF as well as the hydration process will be reduced and negatively affects the compressive strength.

Table 4 Variation of density with different percentages of LF at various curing ages 


\begin{tabular}{|clllll|}
\hline \multirow{5}{*}{ Paste } & \multicolumn{5}{c|}{ Density $\left(\mathbf{g} / \mathbf{c m}^{3}\right)$} \\
\cline { 2 - 6 } & & $\mathbf{1}$ day & $\mathbf{7}$ days & $\mathbf{2 8}$ days & $\mathbf{9 0 ~ d a y s ~}$ \\
& P0 & 2.08 & 2.09 & 2.12 & 2.13 \\
\cline { 2 - 6 } & P5 & 2.06 & 2.08 & 2.09 & 2.1 \\
\cline { 2 - 6 } Mortar & P10 & 2.03 & 2.05 & 2.06 & 2.07 \\
\cline { 2 - 6 } & P15 & 2.09 & 2.11 & 2.13 & 2.14 \\
\cline { 2 - 6 } & P20 & 2.05 & 2.06 & 2.07 & 2.08 \\
\cline { 2 - 6 } & M5 & 2.26 & 2.35 & 2.4 & 2.43 \\
\cline { 2 - 6 } & M10 & 2.25 & 2.31 & 2.36 & 2.42 \\
\cline { 2 - 6 } & M15 & 2.3 & 2.39 & 2.42 & 2.47 \\
\cline { 2 - 6 } & M20 & 2.24 & 2.3 & 2.35 & 2.4 \\
\hline
\end{tabular}

\section{Ultrasonic pulse velocity}

The UPV test is used to check concrete quality. Figs. 13 and 14 show the UPV for pastes and mortars versus curing ages for different percentages of LF. For paste samples, mix 4 with 15\% LF exhibits a higher UPV value with a good quality of paste $(3.88 \mathrm{~km} / \mathrm{s})$ among other mixes. Adding more than $15 \% \mathrm{LF}$ reduces the quality of pastes. This means that whenever the percentage of LF increases beyond this limit, the LF may act as filler and does not contribute to an increase in UPV.

For mortar samples (Fig. 14), mix 3 with 10\% LF displays higher UPV values than the other LF mixes. For example, at 90 days, mix 2,4 , and 5 with 5,15 , and $20 \%$ LF replacement levels display a value of $3.81,3.7$, and 3.73 respectively. However, mix 3 with $10 \%$ LF achieves a value of $3.91 \mathrm{~km} / \mathrm{s}$. It is well noticed that UPV results are consistent with those of compressive strength and chemical shrinkage. Adding 10 and 15\% LF in mortar and paste samples respectively achieve maximum UPV, compressive strength and chemical shrinkage values. Besides, it is shown that UPV values for mortars are mainly greater than those of pastes. For example, the UPV value for a replacement of $10 \% \mathrm{LF}$ in pastes shows a value of $3.78 \mathrm{~km} / \mathrm{s}$ and a value of $3.91 \mathrm{~km} / \mathrm{s}$ for mortar specimens. One possible explanation is that whenever the gel pores between cement and LF increase due to hydration, these voids are replaced by sand leading to a decrease in the time needed for the pulse to get throughout the mortar specimen.

\section{Correlation between different properties}

Figs. 15 and 16 show the correlation between compressive strength and UPV of pastes and mortars respectively for different percentages of $L F$ at 1, 7, 28 and 90 days. This correlation appears to be linear for both pastes and mortars. For pastes, the compressive strength increases with the increase in UPV with a coefficient of determination $R^{2}$ of $0.87,0.87,0.88,0.83,0.83$ for $0,5,10,15$ and $20 \%$ LF respectively. Similarly, a positive correlation with a high coefficient of determination $R^{2}$ above 0.94 for mortar mixes. This indicates that the presence of sand improves the linear correlation.

Additional correlations are shown between the compressive strength and chemical shrinkage at each curing age (Figs. 17 a-d). As chemical shrinkage increases, the compressive strength goes up. A positive correlation with a coefficient of determination $0.8 \otimes R^{2}<0.99$ and $0.75 \otimes R^{2}<0.96$ is shown for paste and mortar samples respectively. For pastes, the highest coefficient of determination is attained at 28 days. However, the highest $R^{2}$ is realized at 90 days for mortars. It is also noted that the linear correlation for paste specimens is stronger than that of mortar specimens. One possible explanation is that the presence of sand in mortar samples (by delaying the hydration process) decreases the chemical shrinkage and accelerates the self desiccation of samples. Therefore, compressive strength will be reduced. (Soroka et al. 1976; Voglis et al. 2005). 
To illustrate the effect of LF on the chemical shrinkage of mortar and pastes, the slope of the regression line determined previously in Fig. 17 versus \% LF is plotted in Fig. 18. It can be observed that the peaks are attained at 10 and $15 \%$ LF for mortars and pastes respectively. Those results are consistent with the chemical shrinkage results obtained previously. Therefore, the optimal percentage of LF as replacement of cement for pastes and mortars is between 10 and $15 \%$ respectively.

\section{Conclusions}

This study is about the influence of incorporating LF on chemical shrinkage of pastes and mortars. Based on the results of this experimental study, the following conclusions can be made:

- Incorporating 5 and 15\% LF enhance the chemical shrinkage for the first 24 hrs for mortars and pastes respectively. Chemical shrinkage for paste samples increases for replacements between 0 and $15 \%$ LF where it achieves the highest value of $0.194 \mathrm{ml} / \mathrm{g}$ of binder followed by a sharp reduction. The chemical shrinkage for mortar increases for replacements between 0 and 10\% LF where it records the highest value of $0.132 \mathrm{ml} / \mathrm{g}$ of binder followed by decline beyond $10 \%$ LF. The chemical shrinkage for pastes samples shows higher values comparing to those for mortar samples. Therefore, the existence of sand affects the hydration process of cement.

- The compressive strength appears to be related to the LF content. The incorporation of $10 \%$ and $15 \%$ LF in mortar and paste samples respectively enhances the compressive strength where it achieves the maximum value of $70.4 \mathrm{MPa}$ in paste specimens and $31.6 \mathrm{MPa}$ in mortar specimens. The values of compressive strength in paste specimens are greater than those for mortar specimens. Therefore, sand affects the compressive strength values.

- The variation of UPV of pastes and mortars depends on LF content. The velocity values for paste increase between 0 and $15 \%$ LF and attains the highest value of $3.88 \mathrm{~km} / \mathrm{s}$ at 90 days. On the other side, for mortar samples, UPV values exhibit an increase between 0 and $10 \%$ LF and display the highest value of $3.91 \mathrm{~km} / \mathrm{s}$ at 90 days. Therefore, the addition of sand alters UPV values.

- The correlation between compressive strength and chemical shrinkage at different curing ages shows a positive correlation with $\mathrm{R}^{2}$ values above 0.75 for pastes and mortars. Similarly, correlation between compressive strength and UPV shows a positive correlation $\left(0.82 \otimes R^{2} \otimes 1\right)$. The higher the strength, the higher the chemical shrinkage and UPV.

\section{Declarations}

Ethics approval and consent to participate: Not applicable.

Consent for publication: Not applicable.

Availability of data and materials: The datasets generated during and/or analysed during the current study are available from the corresponding author on reasonable request.

Competing interests: The authors declare that they have no competing interests.

Funding: This research received no external funding.

Authors' contributions: Conceptualization, J.K.; methodology, R.R.; formal analysis, R.R.; writing - original draft preparation, R.R. and H.G.; writing-review and editing, J.K., H.G. and A.E.; supervision, J.K. and A.E.; project administration, H.G. All authors read and approved the final manuscript.

Acknowledgements: The authors gratefully acknowledge the support received from the staff and technicians working at BAU Laboratories.

\section{References}


1. Adel Mohammed Z, Burhan Abdurrahman R, Ahmad, AH (2010) Influence of limestone powder as partial replacement of cement on concrete and the effect of high temperature on it. Al-Rafidain Engineering Journal (AREJ) 18-5: 24-

34.http://dx.doi.org/10.33899/rengj.2010.32863.

2. Anusha P, Ramya, K (2018) Experimental Study on Concrete with Limestone Powder and Copper Slag. International journal of Engineering Research and Management (IJERM) 5-9: 2349-2058.

3. ASTM C 1608 (2007) Standard test method for chemical shrinkage of hydraulic cement paste. West Conshohocken: American Society for Testing and Materials.

4. ASTM C109 (2016) Standard Test Method for Compressive Strength of Hydraulic Cement Mortars (Using 2-in. or [50mm] Cube Specimens. ASTM International, West Conshohocken, PA.

5. ASTM C188-14 (2014) Standard Test Method for Density of Hydraulic Cement. Annual Book of ASTM standards ASTM International West Conshohocken PA.

6. ASTM C597 (2016) Standard Method for Pulse Velocity through Concrete. ASTM International West Conshohocken PA.

7. Beltzung F, Wittmann F.H (2000) Dissolution of cement and early chemical shrinkage of cement paste. RILEM publications: Switzerland: 91-97.

8. Benabed B, Soualhi H, Belaidi AS, Azzouz L, Kenai S (2016) Effect of limestone powder as a partial replacement of crushed quarry sand on properties of self-compacting repair mortars. Journal of Building Materials and Structures 3-1: 530 .

9. Bentz DP (2006) Modeling the influence of limestone filler on cement hydration using CEMHYD3D. Cement and Concrete Composites 8-2: 124-129.

10. Bentz DP, Irassar EF, Bucher BE, Weiss WJ (2009) Limestone fillers conserve cement, Part 2: durability issues and the effects of limestone fineness on the mixtures. ACI Concrete International 31-12: 35-39

11. Bonavetti V, Donza H, Rahhal V, Irassar E (2000) Influence of initial curing on the properties of concrete containing limestone blended cement. Cement and Concrete Research 30: 703- 708.

12. Bouasker M, Mounanga P, Turcry P, Loukili A, Khelidj A (2008) Chemical shrinkage of cement pastes and mortars at very early age: Effect of limestone filler and granular inclusions. Cement and Concrete Composites 30 -1: 13-22.

https://doi.org/10.1016/j.cemconcomp.2007.06.004.

13. Charron J.P, Marchand J, Bissonnette B (2001) Early-age deformations of hydrating cement systems: comparison of linear and volumetric shrinkage measurements. Concrete Science and Engineering 3: 168-173.

14. Charron J.P,Marchand J,Bissonnette B, PigeonM,ZuberB (2002)

Comparativestudy oftheeffectsofwater/binderratioandsilicafumeonthevolumeinstabilityofhydratingcementpastesatearlyage,InProceedingsofthe3rdInternationalResearchSeminaronSelf-

DesiccationandItsImportanceinConcreteTechnology,Lund,Sweden,PerssonB,FagerlundG,Eds.;LundUniversity:Lund,Sweden: 39-50.

15. Du Kh, Dai Pang S (2020) High-performance concrete incorporating calcined kaolin clay and limestone as cement substitute. Construction and Building Materials 264: 120152. https://doi.org/10.1016/j.conbuildmat.2020.120152.

16. Geiker M, Knudsen T (1982) Chemical shrinkage of Portland cement pastes. Cement and Concrete Composites 12-5:603610. https://doi.org/10.1016/0008-8846(82)90021-7.

17. Güneyisi E, Gesoglu M, Özturan T, Mermerdas K, Özbay E (2011) Properties of mortars with natural pozzolana and limestone-based blended cements. ACI Material Journal 108-5:493-500.

18. Hammer T.A, Heese C (1999) Early age chemical shrinkage and autogenous deformation of cement pastes. In Proceedings of the 2nd International Seminar on Self-Desiccation and Its Importance in Concrete Technology, Lund University, Lund, Sweden:7-13.

19. Heikal H, El-Didamony H, Morsy M.S (2000) Limestone-filled pozzolanic cement. Cement and Concrete Research 30: 18271834.

20. Justnes H (2000) Chemical shrinkage of cement pastes with plasticizing admixtures, Nordic Concrete Research 24: 39-44. 
21. Justnes H, Reyniers B, Sellevold E.J (1994) An evaluation of methods for measuring chemical shrinkage of cementitious pastes, Nordic Concrete Research 14-1: 45-61.

22. Justnes H, Van Gemert A, Verboven F, Sellevold E.J (1996). Total and external chemical shrinkage of low w/c ratio cement pastes. Advances in cement Research 8-31:121-126. https://doi.org/10.1680/adcr.1996.8.31.121.

23. Justnes H, Ardoullie B, Hendrix E, Sellevold E.J, Van Gemert D (1998) The chemical shrinkage of pozzolanic reaction products. Special Publication 178:191-206.

24. Justnes H, Sellevold E.J, Reyniers B, Van Loo D, Van Gemert A, Verboven F, Van Gemert D (1999) The influence of cement characteristics on chemical shrinkage. Autogenous Shrinkage of Concrete. E\&FN Spon, London:71-80.

25. Kovler K, Zhutovsky S (2006) Overview and future trends of shrinkage research. Materials and Structures 39-9 : 827-847.

26. Le Chatelier H (1900) Sur les Changements de Volume Qui Accompagnent le Durcissement des Ciments, Bull. Société de I'Encouragement pour l'Industrie Nationale 5-5 : 54-57.

27. Liao Y, Wei X (2014) Relationship between chemical shrinkage and electrical resistivity for cement pastes at early age. Journal of materials in civil engineering 26-2:384-387. https://doi.org/10.1061/(ASCE)MT.1943-5533.0000851.

28. Livesey P (1991) Strength characteristics of Portland-limestone cements. Construction and Building Materials 5-3:147150.

29. Lothenbach B, Saout G.L, Gallucci E, Scrivener K (2008) Influence of limestone on the hydration of Portland cements. Cement and Concrete Research 38:48-860.

30. Lu T, Li Z, Huang H (2020) Effect of supplementary materials on the autogenous shrinkage of cement paste. Materials 1315: 3367. https://doi.org/10.3390/ma13153367.

31. Lura P (2003) Autogenous deformation and internal curing of concrete. http://resolver.tudelft.nl/uuid:1a1efc2d-a6384787-b543-5bd643a39a4b (accessed on Jun 15-2021).

32. Markandeya A, Mapa D.G, Fincan M, Shanahan N, Stetsko Y.P, Riding K.A, Zayed A (2019) Chemical Shrinkage and Cracking Resilience of Metakaolin Concrete. ACI Materials Journal 116-4. https://doi.org/10.14359/51716714.

33. Matschei T, Lothenbach B, Glasser F.P (2007) The role of calcium carbonate in cement hydration. Cement and Concrete Research 37: 551-558.

34. Meddah M.S, Lmbachiya M.C, Dhir R.K (2014) Potential use of binary and composite limestone cements in concrete production. Construction and Building Materials 58: 193-205. https://doi.org/10.1016/j.conbuildmat.2013.12.012.

35. Menadi B, Kenai S, Khatib J.M, Ait-Mokhtar A (2009) Strength development and prediction of mortars containing limestone fines. SBEIDCO, $1^{\text {st }}$ International Conference on Sustainable Built Environment Infrastructures in Developing Countries ENSET Oran (Algeria): 91-98.

36. Menendez G, Bonavetti V, Irassar E.F (2003) Strength development of ternary blended cement with limestone filler and blast-furnace slag. Cement and Concrete Composites 25:61-67.

37. Persson B (1997) Experimental studies of the effect of silica fume on chemical shrinkage and self-desiccation in Portland cement mortars. Self-Desiccation and its importance in Concrete Technology. Lund, Lund university:116-131.

38. Safiuddin M, Kaish AB, Woon CO, Raman SN (2018) Early-age cracking in concrete: Causes, consequences, remedial measures, and recommendations. Applied Sciences 8-10: 1730.

39. Soroka I, Stern N (1976) Calcareous fillers and the compressive strength of Portland cement. Cement and Concrete Research 6-3:367-376.

40. Tazawa E.I, Miyazawa E.S, Kasai T (1995) Chemical shrinkage and autogenous shrinkage of hydrating cement paste. Cement and concrete research 25-2: 288-292. https://doi.org/10.1016/0008-8846(95)00011-9.

41. Thongsanitgarn P, Wongkeo W, Sinthupinyo S, Chaipanich A (2012) Effect of limestone powders on compressive strength and setting time of Portland-limestone cement pastes. In Advanced Materials Research 343:322-326. Trans Tech Publications Ltd. 
42. Tsivilis S, Batis G, Chaniotakis E, Grigoriadis Gr, Theodossis D (2000) Properties and behavior of limestone cement concrete and mortar. Cement and Concrete Research 30: 1679-1683.

43. Voglis N, Kakali G, Chaniotakis E, Tsivilis S (2005) Portland-limestone cements. Their properties and hydration compared to those of other composite cements. Cement and Concrete Composites 27-2: 191-196.

44. Wang C, Wang Y.W, Pu X.C (2010) Autogenous shrinkage characteristics and mechanism of ultra-low water cement concrete. Journal of Building Materials 1: 75-79. http://dx.doi.org/10.3969/j.issn.1007-9629.2010.01.016.

45. Wang D, Shi C, Farzadnia N, Shi Z, Jia H (2018a) A review on effects of limestone powder on the properties of concrete. Construction and building materials 192: 153-66.

46. Wang D, Shi C, Farzadnia N, Shi Z, Jia H, Ou Z (2018b) A review on use of limestone powder in cement-based materials: Mechanism, hydration and microstructures. Construction Building Materials 181: 659-72.

47. Wang J, Cheng Y, Yuan L, Xu D, Du P, Hou P, Zhou Z, Cheng X, Liu S, Wang Y (2020) Effect of nano-silica on chemical and volume shrinkage of cement-based composites. Construction and Building Materials 247: 118529. https://doi.org/10.1016/j.conbuildmat.2020.118529.

48. Weerdt k.D, Haha M.B, Le Saout G, Kjellsen K.O, Justnes H, Lothenbach B. Hydration mechanisms of ternary Portland cements containing limestone powder and fly ash (2011). Cement and Concrete research 41-3:279-291. https://doi.org/10.1016/j.cemconres.2010.11.014.

49. Weerdt K.D, Justnes H, Kjellsen KO (2010) Fly ash-limestone ternary composite cements: synergetic effect at 28 days. Nordic Concrete Research 42-2: 51-70.

50. Wild S, Khatib J.M, Roose L.J (1998) Chemical shrinkage and autogenous shrinkage of Portland cement - metakaolin pastes. Advances in cement research 10-3: 109-119. https://doi.org/10.1680/adcr.1998.10.3.109.

51. Zhang Z, Scherer GW (2020) Measuring chemical shrinkage of ordinary Portland cement pastes with high water-to-cement ratios by adding cellulose nanofibrils. Cement and Concrete Composites 111: 103625.

52. Zhang J, Weissinger EA, Peethamparan S, Scherer GW (2010) Early hydration and setting of oil well cement. Cement and Concrete research 40-7:1023-1033.

53. Zhang T, Gao P, Luo R, Guo Y, Wei J, Yu Q (2013) Measurement of chemical shrinkage of cement paste: Comparison study of ASTM C 1608 and an improved method. Construction and Building Materials 48: 662-669. https://doi.org/10.1016/j.conbuildmat.2013.07.086.

54. Zhutovsky S, Kovler K (2008) Revised view on chemical shrinkage, In International Conference on Microstructure Related Durability of Cementitious Composites: 775-784.

55. Zhutovsky S, Kovler K (2010) Chemical shrinkage of high-strength/high-performance cementitious materials. Int Rev Civil Eng: 110-118. https://doi.org/10.15866/ireche.v10i1.15794.

\section{Figures}




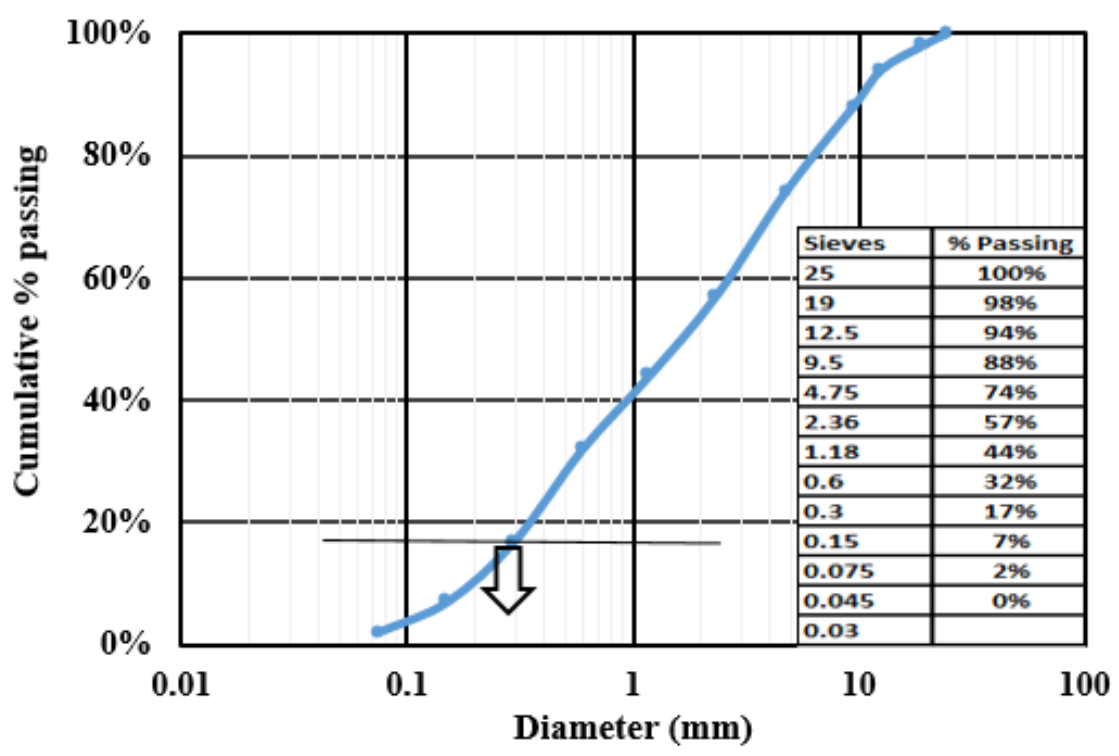

Figure 1

Particle size distribution of LF

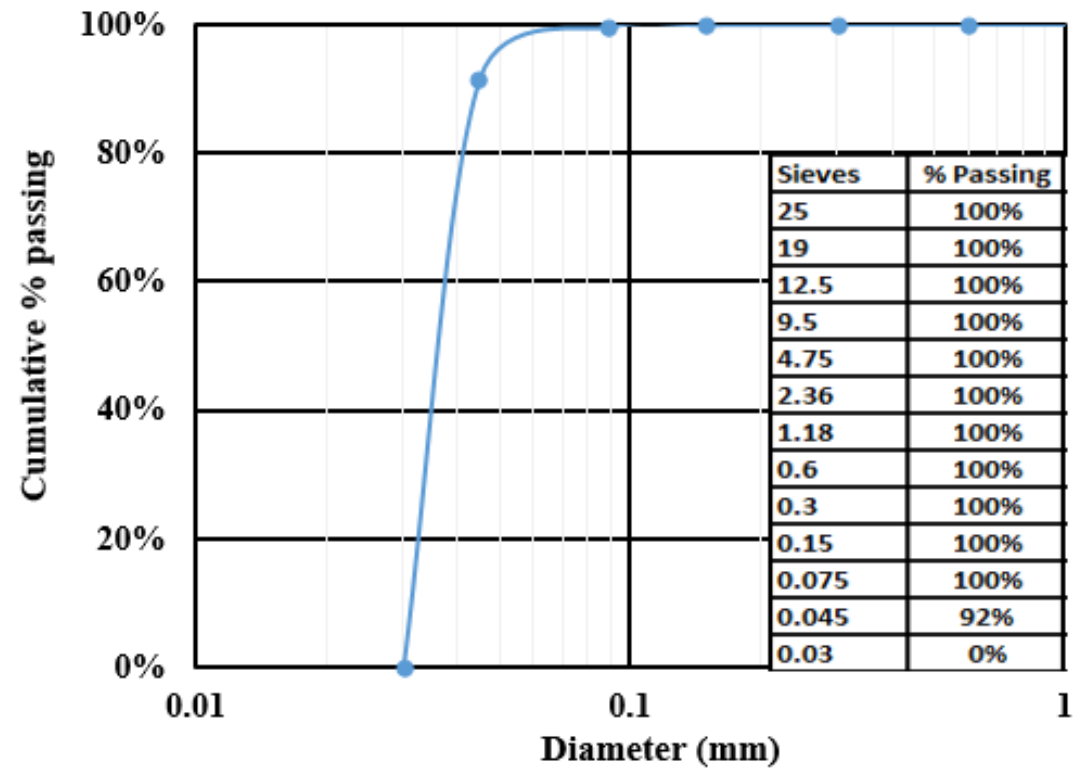

Figure 2

Particle size distribution of cement 


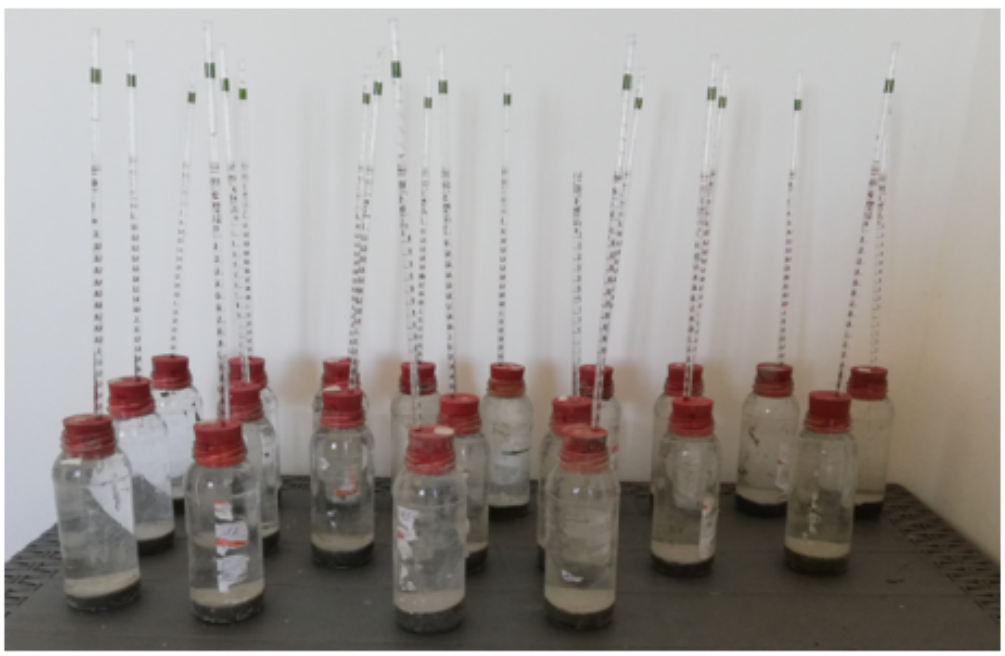

\section{Figure 3}

Chemical shrinkage specimens for pastes and mortars

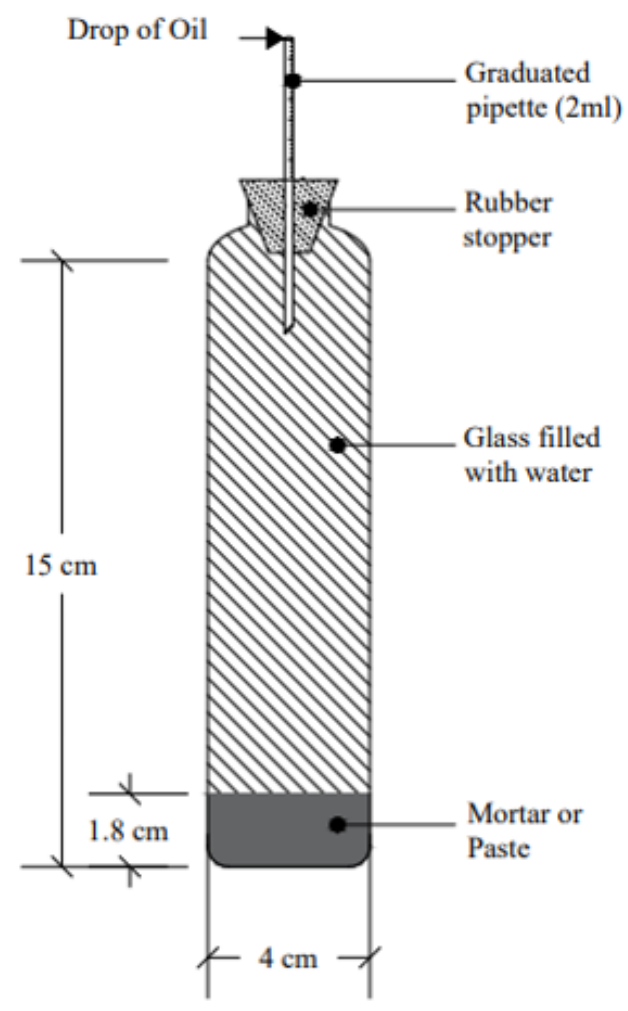

\section{Figure 4}

Chemical shrinkage measurements setup 


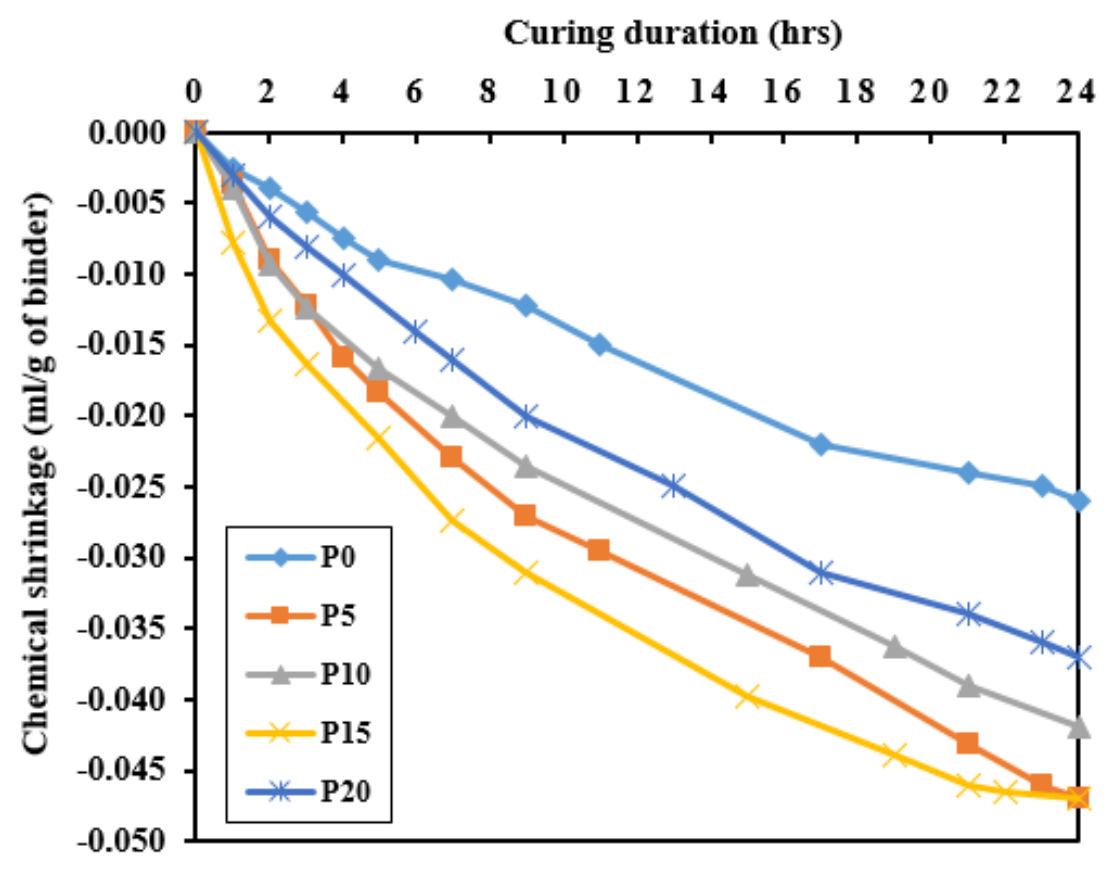

Figure 5

Chemical shrinkage of pastes during the first $24 \mathrm{hrs}$

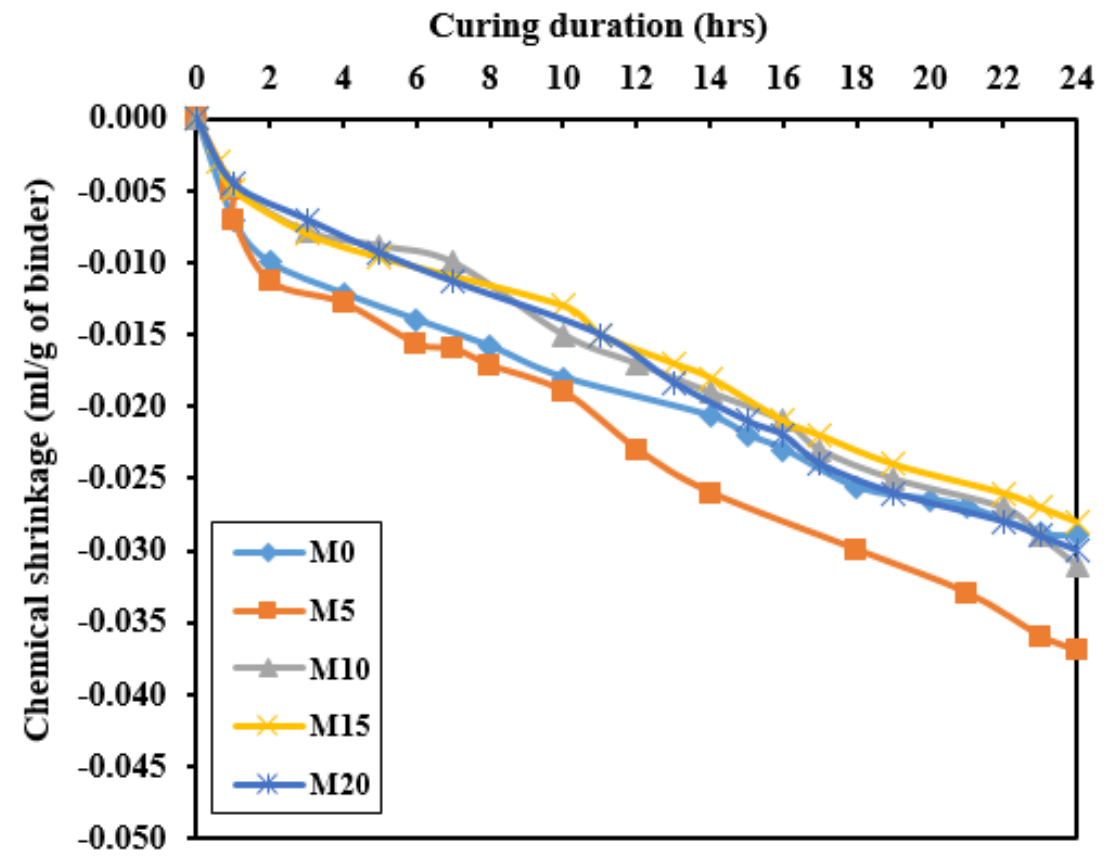

Figure 6

Chemical shrinkage of mortars during the first $24 \mathrm{hrs}$ 


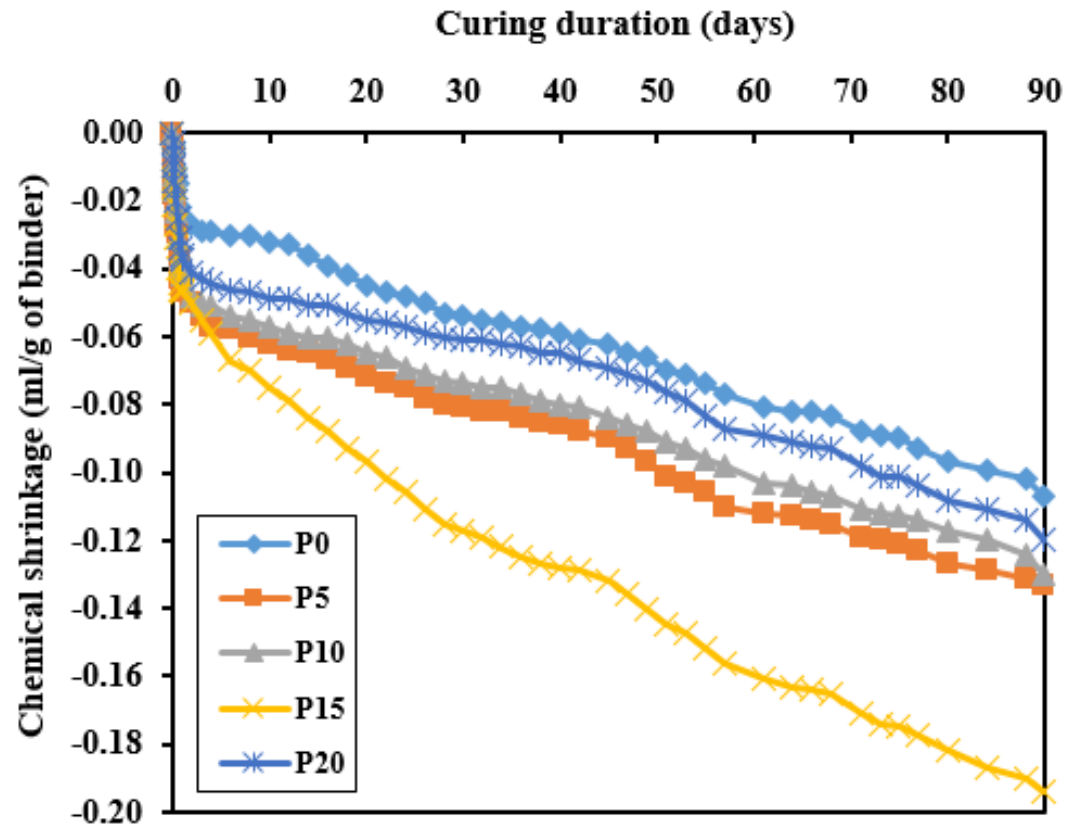

Figure 7

Chemical shrinkage of pastes up to 90 days

Curing duration (days)

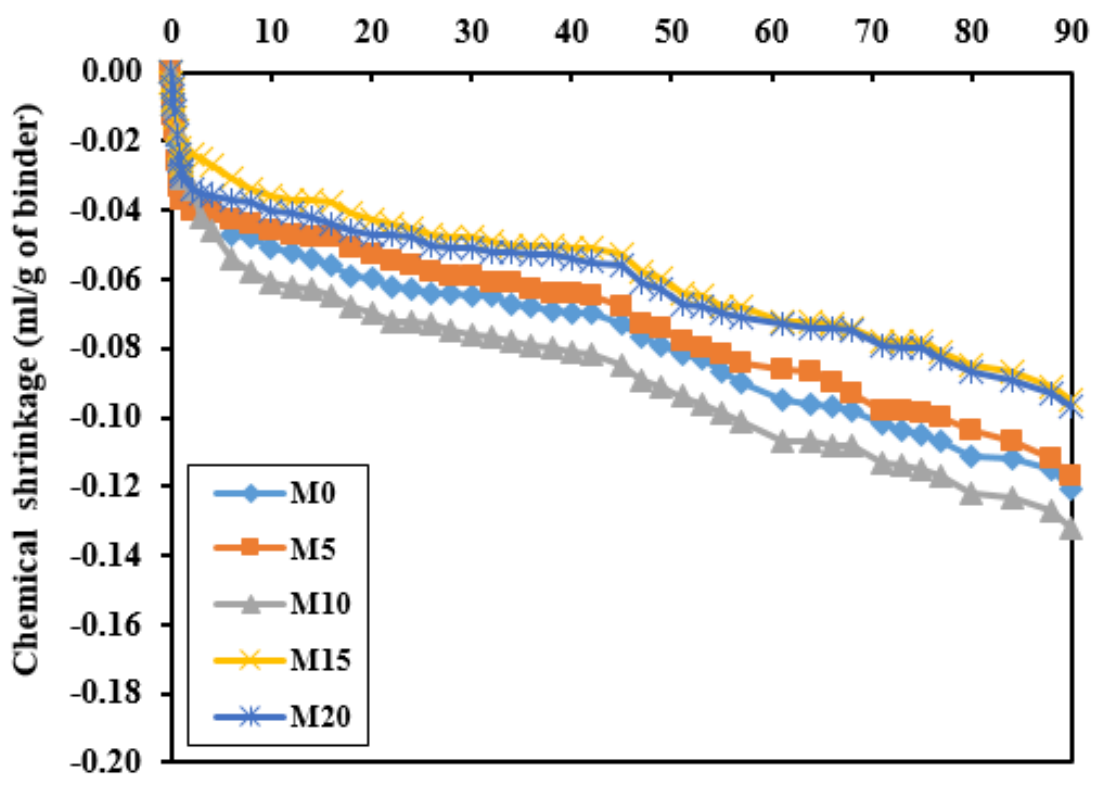

Figure 8

Chemical shrinkage of mortars up to 90 days 


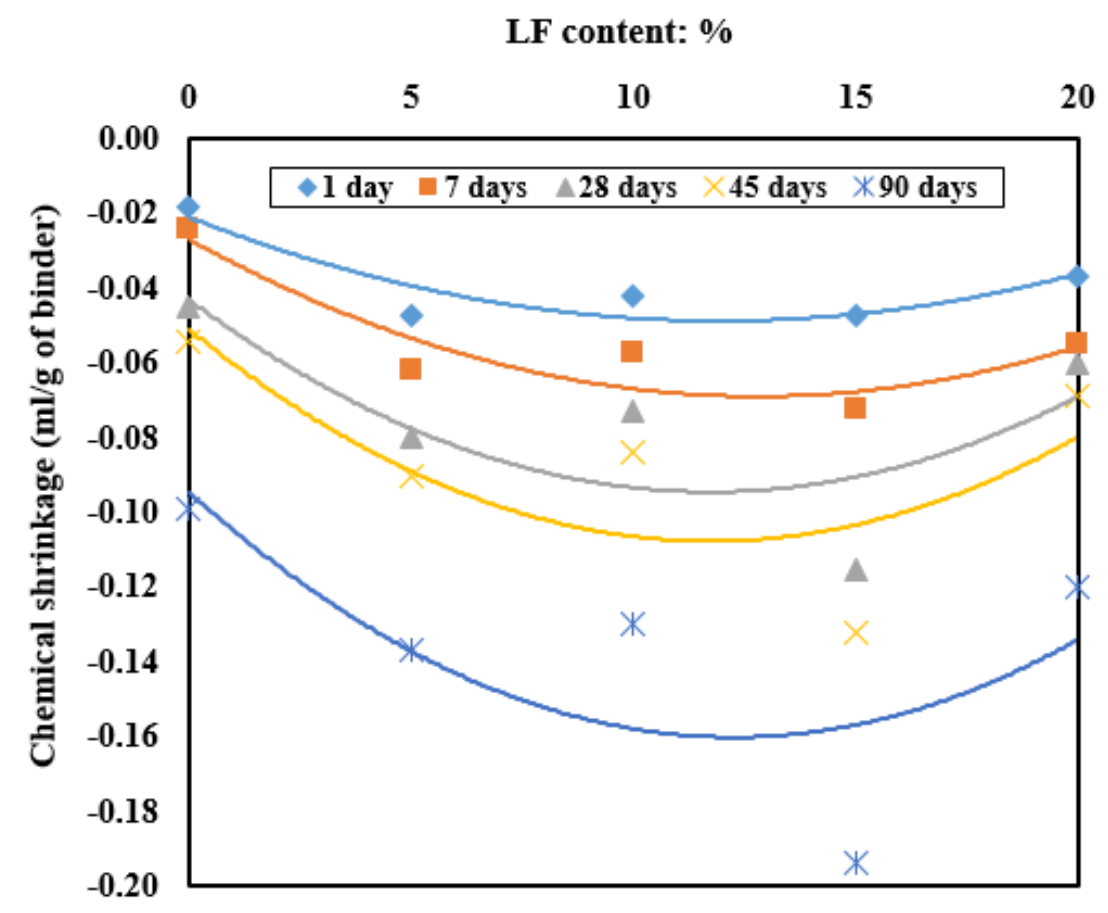

Figure 9

Chemical shrinkage of pastes at various durations

LF content: \%

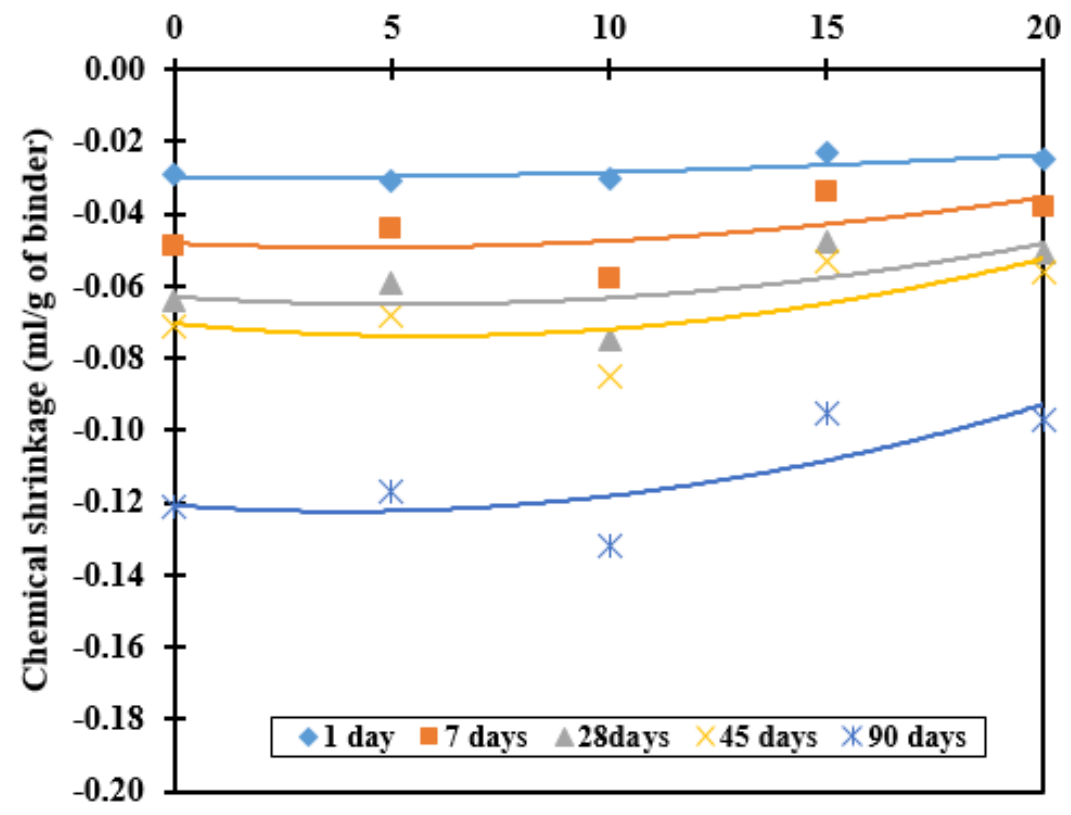

Figure 10

Chemical shrinkage of mortars at various durations 


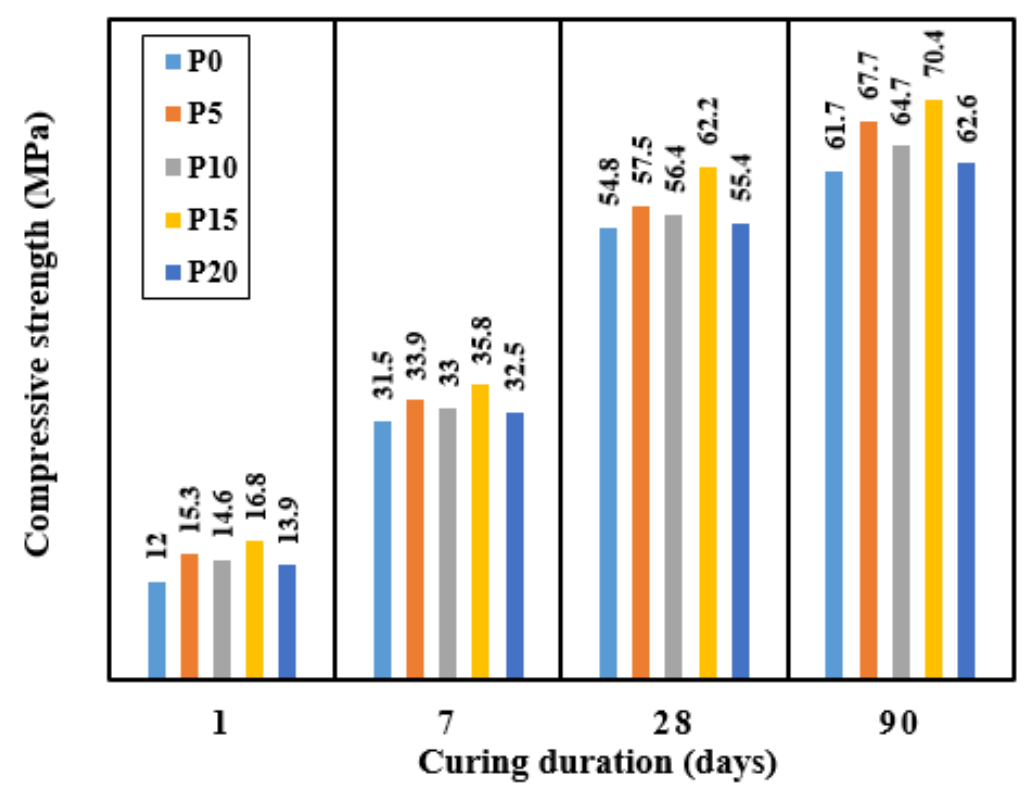

Figure 11

Compressive strength of pastes at different curing ages

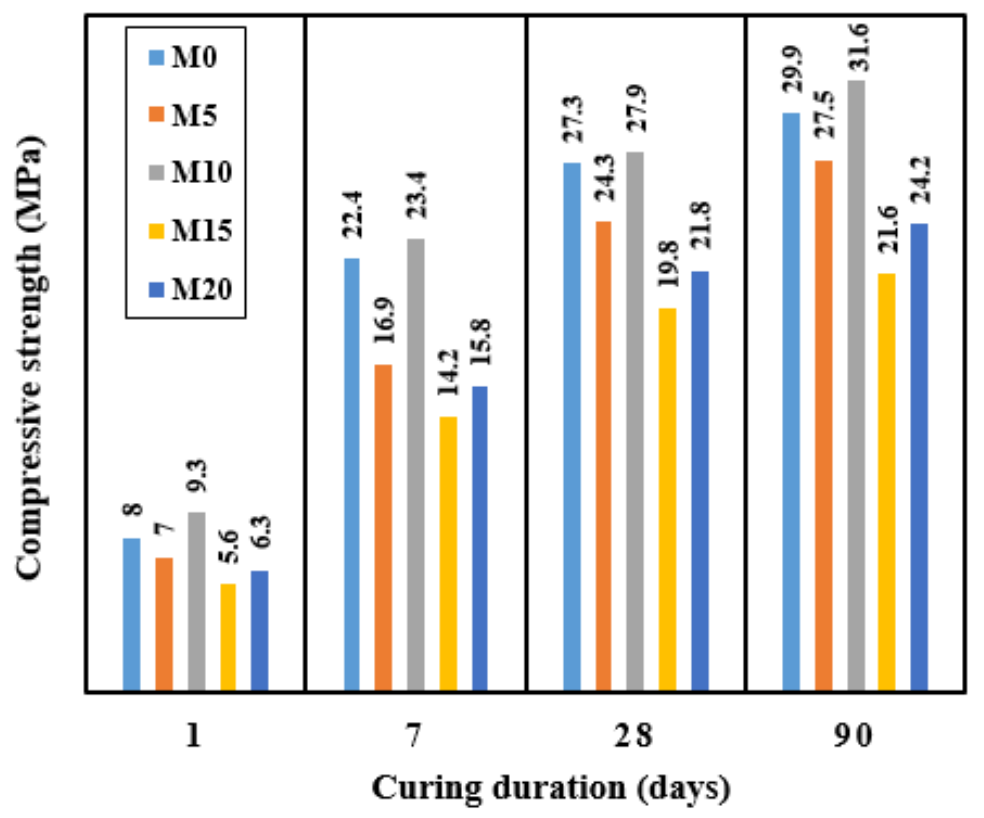

Figure 12

Compressive strength of mortars at different curing ages 


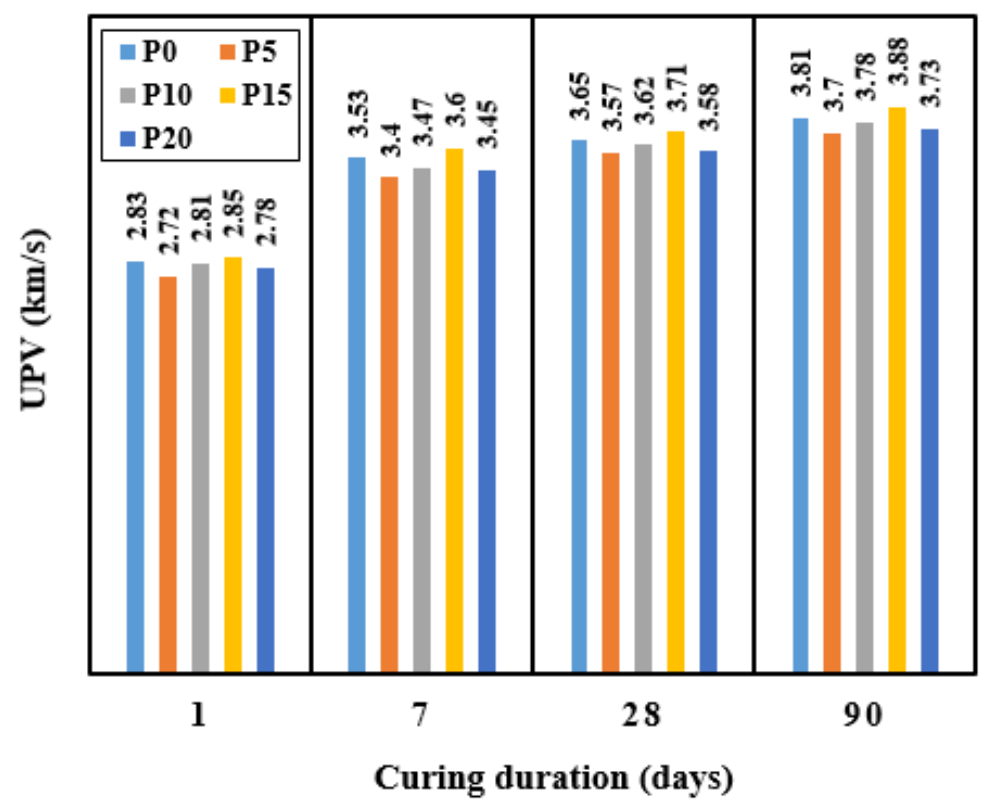

Figure 13

Variation of UPV for pastes at different curing ages

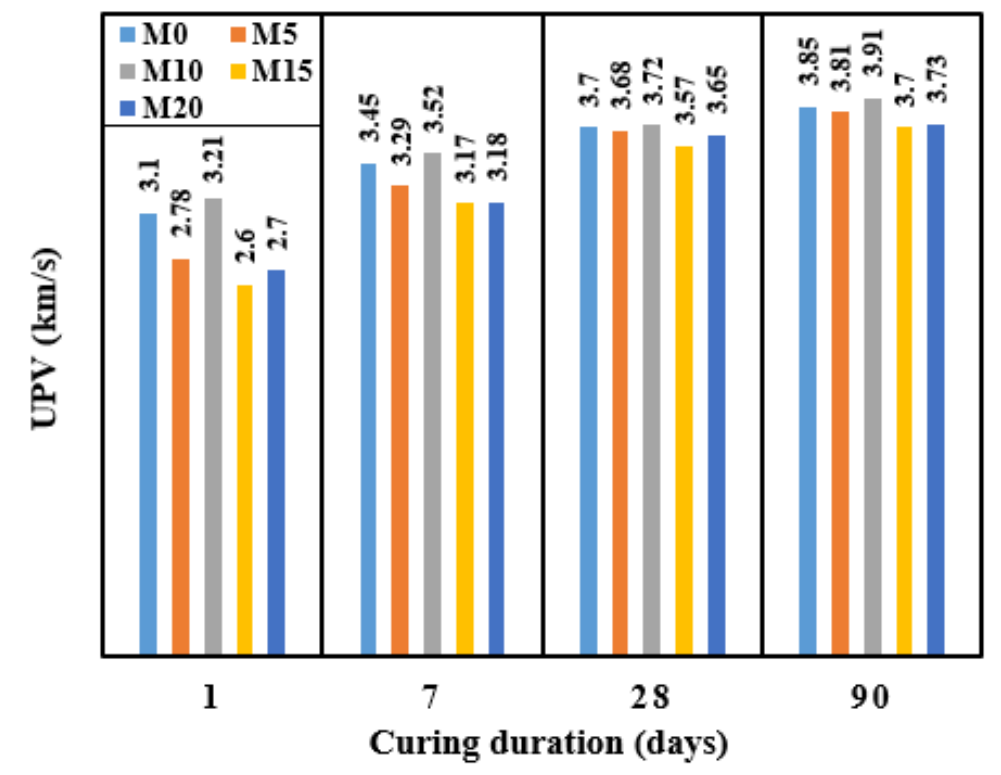

Figure 14

Variation of UPV for mortars at different curing ages 


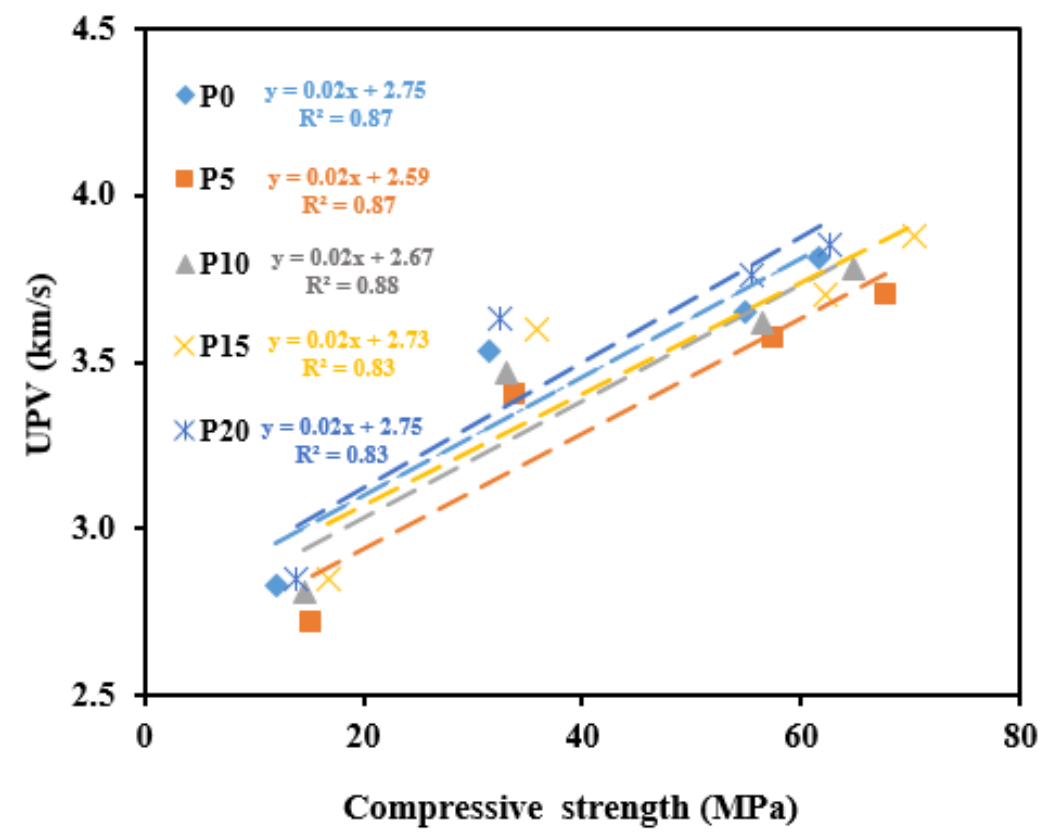

Figure 15

Correlation between compressive strength and UPV for pastes

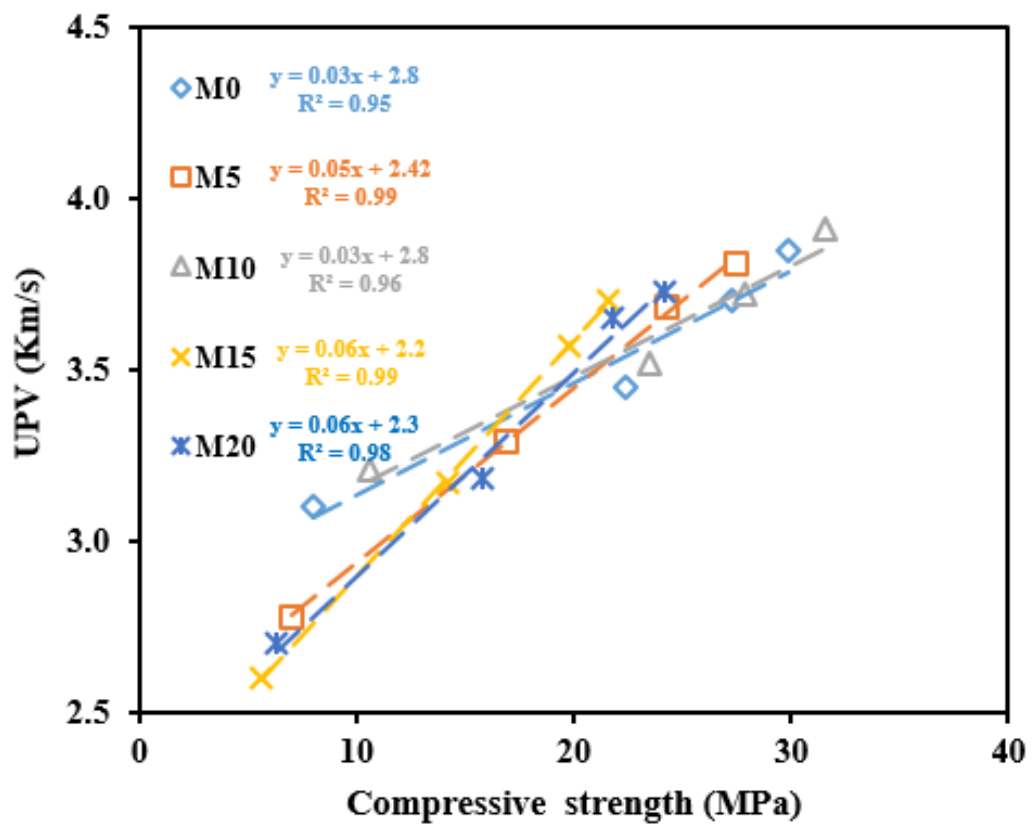

Figure 16

Correlation between UPV and compressive strength for mortars 


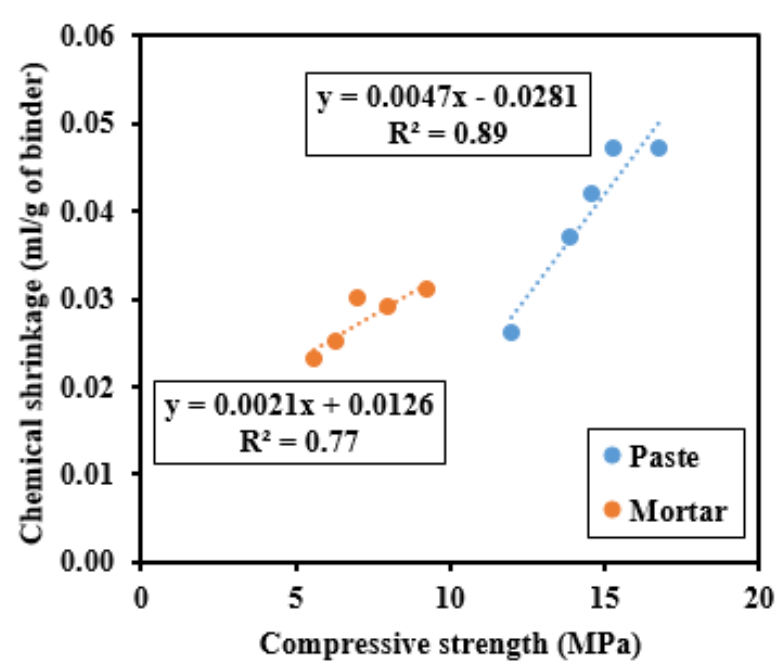

(a)

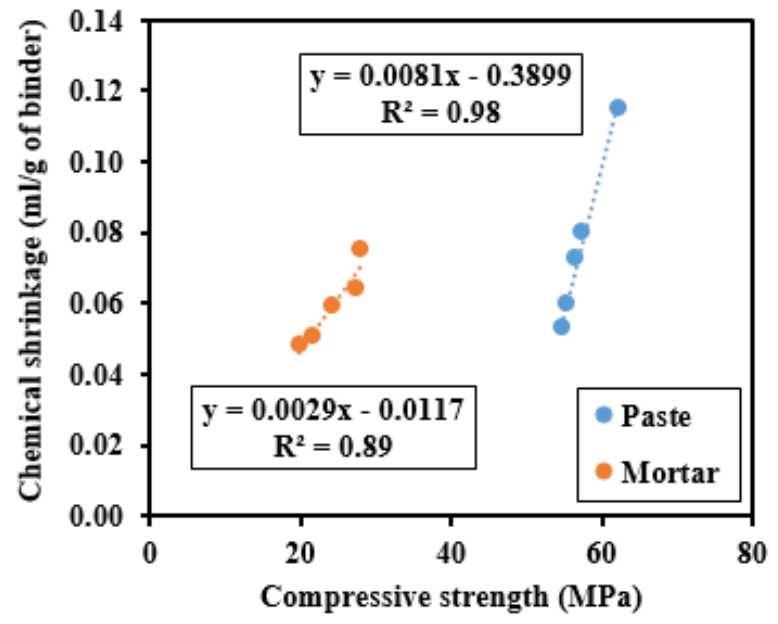

(c)

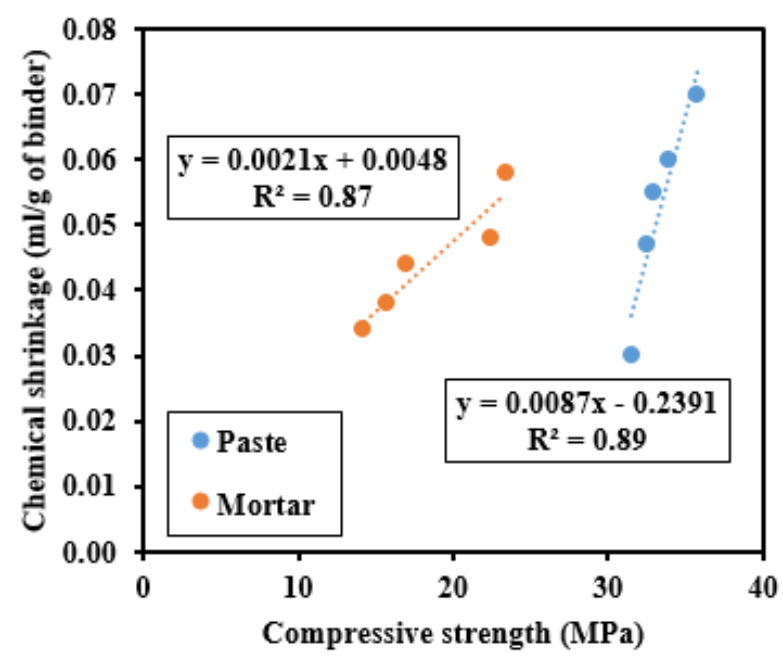

(b)

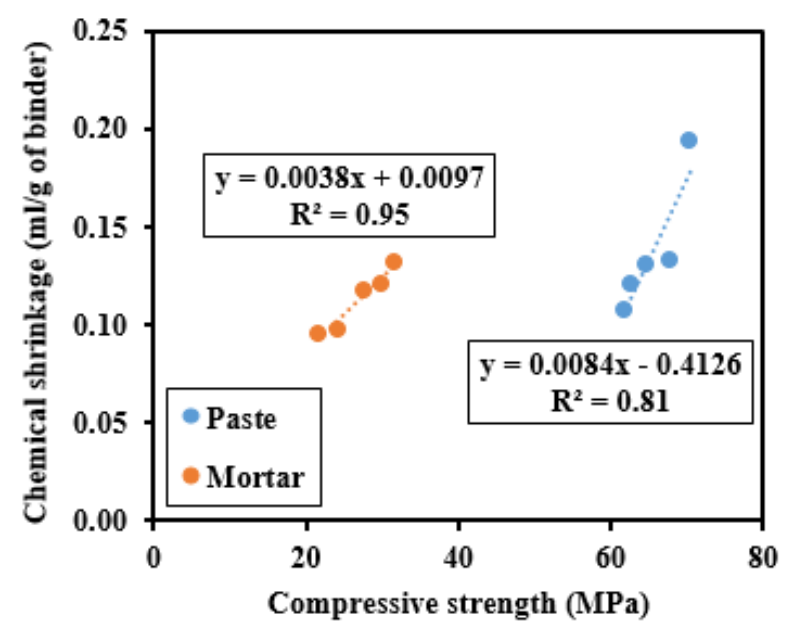

(d)

\section{Figure 17}

Correlation between chemical shrinkage and compressive strength for pastes and mortars at different ages. (a) 1 day, (b) 7 days, (c) 28 days and (d) 90 days 


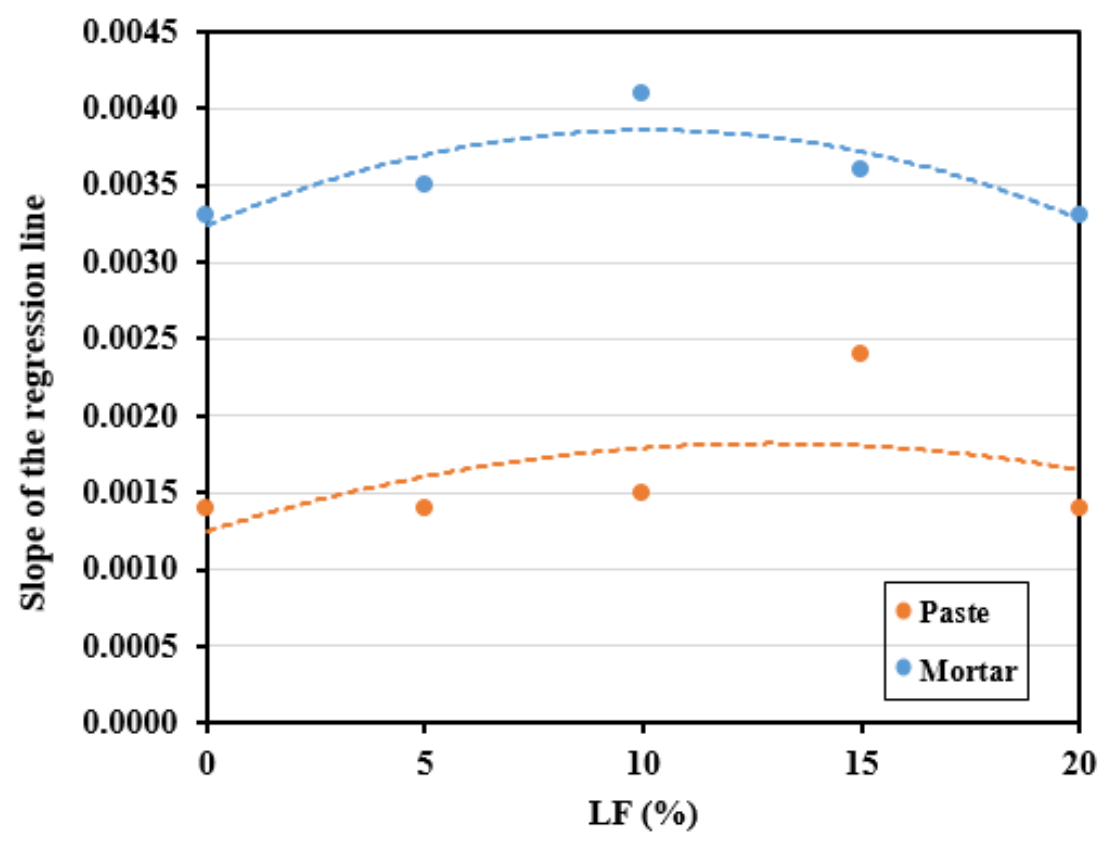

Figure 18

Correlation between the slope of the regression line and percentages of LF 